\title{
Eski ve Yeni Üniversite Yapılarında Enerji Verimliliği
}

\author{
Furkan İbanoğlu ${ }^{1}$, Mustafa Atmaca ${ }^{2}$, Ahmet Berk Kurtuluş ${ }^{3}$ \\ ${ }^{1,2,3}$ Marmara Üniversitesi, Teknoloji Fakültesi, Makine Mühendisliği Bölümü, Göztepe Kampüsü,34722, İstanbul, \\ Türkiye
}

\section{Özet}

$\mathrm{Bu}$ çalışmada, eski ve yeni mimari yapıdaki binaların enerji verimliliği açısından aralarındaki farklar incelenmiştir. Marmara Üniversitesi Göztepe Kampüsü’nde bulunan eski ve yeni; iki farklı fakülte binasında yapılan ölçümler sunulmuştur. İç ve dış ortamların sıcaklık ölçümleri yapılmıştır. Ölçümler özellikle kış aylarında saatlik alınmıştır. Yetersiz cam kullanımından, kötü ve kalitesiz malzemeyle yapılmış pencere ve duvarlardan kaynaklanan binalarda büyük öneme sahip ısıtma kaybının enerji etkinliğine özel bir dikkat çekilmeye çalışılmıştır.

Anahtar Kelimeler: Enerji Verimliliği, Isı Kayıpları, Eski ve Yeni Kamu Binası, Sıcaklık.

\section{Investigation of the Energy Efficiency of Old and New University Buildings}

\begin{abstract}
In this study, the differences between the old and new public buildings were investigated in terms of energy efficiency. Measurements carried out old and new in two different faculty buildings were presented located on of Marmara University Goztepe Campus. Indoor and outdoor temperature measurements were implemented. Measurements were taken hourly, especially during the winter months. A special attention was paid to pull both heat loses resulting from inadequate use of glass, poor or material made from the windows and energy efficiency of the building's facade.
\end{abstract}

Key Words: Energy efficiency, Heat loses, Old and new public building, Temperature.

\section{Giriş}

Ülkelerin hızla kalkınması ve üçüncü dünya ülkelerinin modern enerji kaynaklarına ulaşması sonucunda dünya toplam enerji ihtiyacı her geçen gün artmakta ve nihayetinde enerji, çağımızın en önemli stratejik değeri haline gelmektedir [1]. Uluslararası Enerji Ajansı'na göre, araştırmalar göstermektedir ki binalar, en önemli enerji tüketen unsurlardan biri olarak dünyada toplamda kullanılan elektriğin yarısını, doğalgazın ise üçte birini tüketirken, ayrıca toplamda atmosfere salınan sera gazlarının da üçte birinden sorumludurlar [2]. Türkiye'nin 2006 yılında 176.2 milyar kWh olan elektrik tüketimi 2007 y1lında \%7.8 artışla 191.6 milyar kWh'ye ulaşmıştır. 2003-2007 döneminde Türkiye'nin elektrik enerjisi tüketim artış1 \%43'tür. Bu artış dünya ülkeleri arasında en yüksek artışlardan biridir [3]. Avrupa ülkelerinde ise bu değer yaklaşı olarak $50 \mathrm{kWh} / \mathrm{m}^{2}$, dir. Gelişmiş ülkelerde konut ve binalarda enerjinin daha verimli kullanılması sayesinde enerji tüketimine olumlu yönde katkıs1 $\% 20$ ve $\% 40$ değerleri arasındadır. Son iki yılda temel enerji verilerine göre $\mathrm{CO}_{2}$ emisyonu \%40'dan \%43'e çıkmıştır. Şu anki tahminler, bu büyüme trendinin devam edeceği yönündedir [4]. Öte yandan ortalama \%20-30 oranında azaltılan enerji kullanımı; 1s1 yalıtımı, düşük 1S1 geçirme özellikli pencereler, pencere çıkıntıları ve gün ışı̆̆ kontrolü olarak da adlandırılan gündüz aydınlatma kontrolleri gibi geleneksel enerji verimliliği teknolojileri, yeni binalarda

Sorumlu yazar/Corresponding author: Mustafa ATMACA Tel: 0216-336-57-70/1315, e-posta: matmaca@marmara.edu.tr 
enerji kullanımını azaltmak için kullanılabileceğini gösterilmiş ve bazı bina türleri ve yerler için bu oran $\%$ 40'a kadar ulaşmıştır [5-7].

Ülkemizde ise enerjinin \%35-40' 1 binalarda tüketilmekte ve bu değerin $\% 85^{\prime}$ i ise binaların 1sıtılması amacıyla kullanılmaktadır. Isı yalıtım önlemlerinin alınması ile bu kayıplar azaltılması mümkün olabilmektedir. Bina yalıtımı ile \%25'ten \%50'ye varan yakıt tasarrufu sağlanması mümkündür [8]. Ülkemizde yaygın olarak uygulanan bina mimarisi ve yapım tekniğinde, 1sıtma ve soğutma parametreleri öncelikli olarak ele alınmamaktadır. Bu uygulama binaların enerji ihtiyacını; dolayısı ile yakıt tüketimini, çevre kirliliğini, 1sıtma ve soğutma amaçlı ilk yatırım ve işletme maliyetlerini arttırmaktadır. Türkiye gibi enerji üretim ve tüketim oranları arasında büyük fark olan ülkeler için enerjinin etkili bir biçimde kullanılması çok önemlidir. Türkiye'de kullanılan enerjinin \%40 gibi büyük bir kısmı 1sıtmada, 1sıtmadan daha fazlası ise bazı bölgelerimizde soğutma amaçlı kullanılmaktadır. Çünkü binalara uygulanan 1s1 yalıtımı yok denecek kadar azdır. 1998 ve 2000 yıllarında yürürlüğe giren 1s1 yalıtım kurallarına göre yapılan binaların enerji performansı, benzer iklim koşullarına sahip Avrupa ülkelerine göre daha düşüktür [9]. Bu durum dikkate alınarak 2008 yılında TS 825 Binalarda Isı Yalıtım Kuralları Standardında değişiklikler yapılmış, 2000 yılında yürürlüğe giren ve değişik tarihlerde revize edilen "Binalarda Isı Yalıtım Yönetmeliği”" yürürlükten kaldırılmış yerine "Binalarda Enerji Performansı Yönetmeliği” (BEPY) çıkartılmıştır. Ülkemizde enerji verimliliğinin arttırılması için yasal mevzuat sıkılaştırılmıştır. Ekonomik gelişmeler ve yasal düzenlemelerin binalarda 1sı yalıtımını zorunlu kılması bu alanda yapılan bilimsel çalışmaların hızlanmasına neden olmuştur [10]. En basit anlamda enerji verimliliği, aynı iç sıcaklıkları sağlamak için binayı dıştan yalıtmaktır ki bu hem soğutma döneminde hem de 1sıtma döneminde avantaj sağlamaktadır. Binalar, kullanıcı konforundan ödün vermeden enerjiyi etkin ve minimal değerlerde kullanabilmeyi sağlayarak iç ve dış ortam koşullarındaki değişimleri algılamalı, değişimlere anında cevap verebilmeli ve koşullara uyum sağlayabilmelidir [11].

Çalışma kapsamında örnek olarak İstanbul' da bulunan eski ve yeni, iki farklı kamu binasında (üniversite fakülte binalarında) yapılan ölçümler sunulmaktadır. Sıcaklık ölçümleri kış mevsiminde belirli bir periyotta saatlik olarak yapılmıştır. Yetersiz cam kullanımından, kötü ve kalitesiz malzemeyle yapılmış pencerelerden kaynaklanan binalarda büyük öneme sahip 1sı kaybının yanı sıra cephenin enerji etkinliğine de özel bir dikkat çekilmeye çalışılmıştır. Çalışma içerisinde yapılan ölçümlerle enerji kayıpları incelenmiştir. Isınma için enerji tüketimi ölçümleri ile hesaplanan değerler karşılaştırılmıştır. Buna göre farklı tarihlerde ve farklı malzeme yapısının enerji verimliliği açısından incelenmesi sağlanmış olmaktadır. Sonuç kısmında ise yapılan ölçümlere bağlı kalınarak elde edilen veriler ışığında binalarda daha verimli enerji kullanımına dair öneriler sunulmaktadır. [12]

\section{Materyal ve Yöntem}

Çalışmada ölçümler için meteoroloji seti kullanılmıştır. Bu meteoroloji seti ile iç ve dış ortama ait özelliklerin anlık olarak belirlenmesi ve değişimlerinin izlenmesi amaçlanmıştır. İç ortamda; ortam içerisinde kapalı hacimde sıcaklık ve nem ölçümü gerçekleştirilirken dış ortamda; berlirlenen katlardaki dış cepheye montaji yapılarak sıcaklık ve nem verileri kaydedilmiştir. Bir meteoroloji istasyonu, ana konsol ünitesi ve termo-higro sensörden oluşmaktadır. Ana konsol ünitesi iç ortama yerleştirilir ve iç mahalin sıcaklık ve nem ölçümlerini alır. Termo-higro sensör ise dış cepheye yerleştirilerek yapıdaki katların hemen dış ortamındaki değerleri kaydeder.

Meteroloji istasyonunun teknik özellikleri Tablo 1'de verilmiştir.

Farklı iki kamu binasının kuzey ve güney tarafındaki dış cephelerine ayrı ayrı katlara konulmak suretiyle sıcaklık sensörleri yerleştirilmiştir. Yerleştirilen sensörler bir hafta boyunca yarım saatlik periyotlar 
halinde otomatik olarak sıcaklık ölçümü yapmıştır. İki binada iç mekanlara yerleştirilen sensörlerden veri alıp kaydeden aynı zamanda bulunduğu iç mekanın sıcaklık nem oranı verilerini ölçüp kaydeden ana konsollar yerleştirilmiştir. Sensörlerin topladığ1 tüm veriler $433.92 \mathrm{MHz}$ telsiz radyo frekans1 üzerinden ana konsola aktarılarak değerlerin depolanması sağlanır. Hava istasyonu en çok 5 termo-higrometreyi destekler. Bu durum da 5 kanal sicaklık ve nem gösterimine denk gelir.

Tablo 1. Meteoroloji İstasyonunun Teknik Özellikleri

\begin{tabular}{|c|c|}
\hline \multicolumn{2}{|c|}{ Meteoroloji İstasyonunun Teknik Özellikler } \\
\hline RF İletişim Frekansı & $433.92 \mathrm{MHz}$ \\
\hline RF Alım Aralığı-Termo-higro Sensörü & En çok 100 metre (Görüş Alanında ) \\
\hline Barometrik Basınç Aralığ & $500 \mathrm{hpa} \mathrm{..} \mathrm{1100hpa} \mathrm{(} 14.75 \mathrm{inHg} . .32 .44 \mathrm{inHg})$ \\
\hline Barometrik Basınç Aralığı-Deniz seviyesinde & $374.5 \mathrm{mmHg} \ldots 823.8 \mathrm{mmHg}$ \\
\hline Barometrik Basınç Çözünürlüğü & $0.1 \mathrm{hpa}(0.003 \mathrm{inHg}, 0.08 \mathrm{mmHg})$ \\
\hline Barometrik Basınç Doğruluğu & $\pm 3 \mathrm{hpa}(0.009 \mathrm{inHg}, 2.3 \mathrm{mmHg})$ \\
\hline Harici Sıcakl1k Gösterge Aralığ 1 & $-40^{\circ} \mathrm{C}-80^{\circ} \mathrm{C}^{\prime}$ \\
\hline Dahili Sıcaklık Gösterge Aralığ & $-9.9^{\circ} \mathrm{C}-60^{\circ} \mathrm{C}$ \\
\hline Sicaklık Doğruluğu & $\pm 1^{\circ} \mathrm{C}$ \\
\hline Sicaklık Hassasiyeti & $0.1^{\circ} \mathrm{C}$ \\
\hline Nem Gösterge Aralığ 1 & $\% 0$... \%99 Bağıl Nem \\
\hline Nem doğruluğu & $\% \pm 5(\% 25-\% 80$ dahilinde $)$ \\
\hline Nem Hassasiyeti & $\% 1$ değerinde \\
\hline Sicaklık Hissetme Döngüsü (iç mekan) & $10 \mathrm{~s}$ \\
\hline Nem Hissetme Döngüsü (iç mekan) & $10 \mathrm{~s}$ \\
\hline
\end{tabular}

Farklı iki kamu binasının kuzey ve güney tarafındaki dış cephelerine ayrı ayrı katlara konulmak suretiyle sıcaklık sensörleri yerleştirilmiştir. Yerleştirilen sensörler bir hafta boyunca yarım saatlik periyotlar halinde otomatik olarak sıcaklık ölçümü yapmıştır. İki binada iç mekanlara yerleştirilen sensörlerden veri alıp kaydeden aynı zamanda bulunduğu iç mekanın sıcaklık nem oranı verilerini ölçüp kaydeden ana konsollar yerleştirilmiştir. Sensörlerin topladığı tüm veriler $433.92 \mathrm{MHz}$ telsiz radyo frekansı üzerinden ana konsola aktarılarak değerlerin depolanması sağlanır. Hava istasyonu en çok 5 termo-higrometreyi destekler. Bu durum da 5 kanal sicaklık ve nem gösterimine denk gelir.

\subsection{Ana konsol ünitesi}

Ana konsol ünitesi radyo kontrollü hassasiyette alarmlı saat ve hava tahmini özelliklerine haizdir. İç mekan sıcaklık ve nemini ölçer, harici sensörlerden hava tahmin verilerini gösterir. Aynı zamanda iç/dış mekan sıcaklığı, basınç ve nem eğilimi ile ay hareketlerini (ay fazı, gün batımı/doğumu) sağlar. Ana konsol bilgisayar bağlantısı olmadan yaklaşık 3300 hava tahmin değerini kaydeder. Ünite ile birlikte gelen yazılım ve USB kablo ile bilgisayara bağlanınca sınırsız sayıda hava tahmin değeri gösterilip bilgisayara kaydedilebilmektedir [13]. 


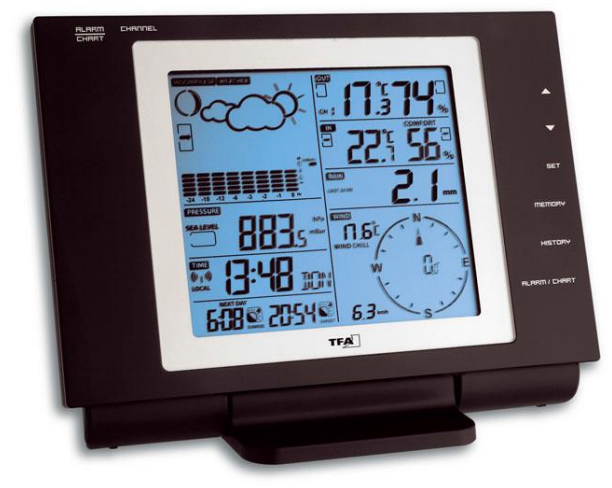

Şekil 1. Ana Konsol Ünitesi

\subsection{Termo-higro sensör}

Farklı iki kamu binasının kuzey ve güney taraftaki dış cephelerine çeşitli katlara sensörler konulmak suretiyle sıcaklık ölçümleri yapılmıştır. Yerleştirilen bu sensörler üç gün süresince yarım saatlik periyotlar halinde otomatik olarak sıcaklık ölçümü yapmıştır.

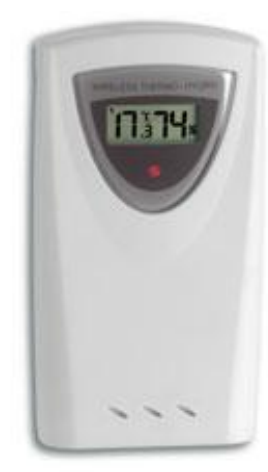

\section{Şekil 2. Termo-Higro Sensör}

Şekil 3 ve 4'te termo-higro sensörün ölçüm alınan eski kamu binası olan Teknik Eğitim Fakültesi A Blok ve yeni yapılmış kamu binası olan Mühendislik Fakültesi C Blokta cepheden görünümleri verilmiştir. Mühendislik Fakültesi binası yenilenme sürecine girmiş ve TS 825'e göre esas alınmış bir yapıyken Teknik Eğitim Fakültesi yapım yılının çok daha eski olduğu bilinmektedir. 

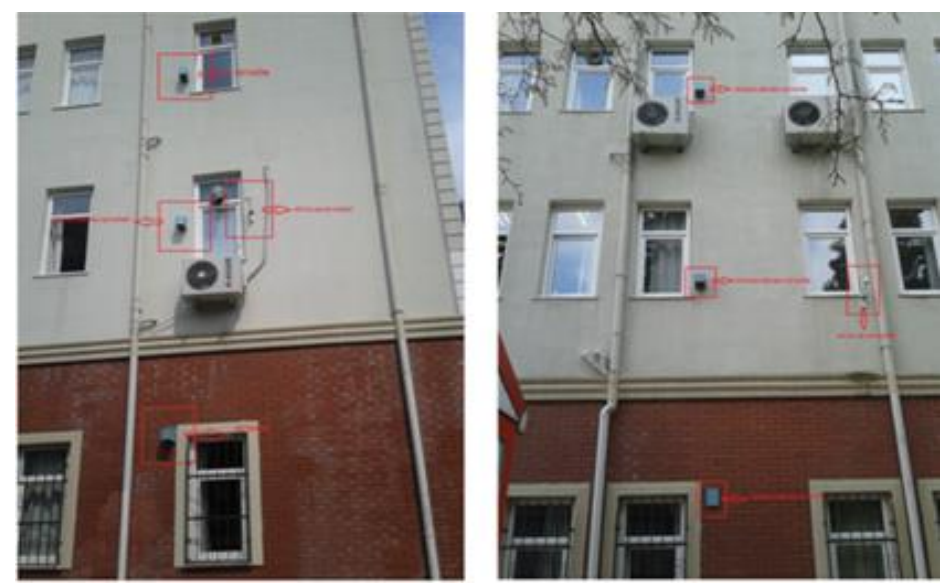

Şekil 3. Mühendislik Fakültesi C Blok Cepheden Görünüm
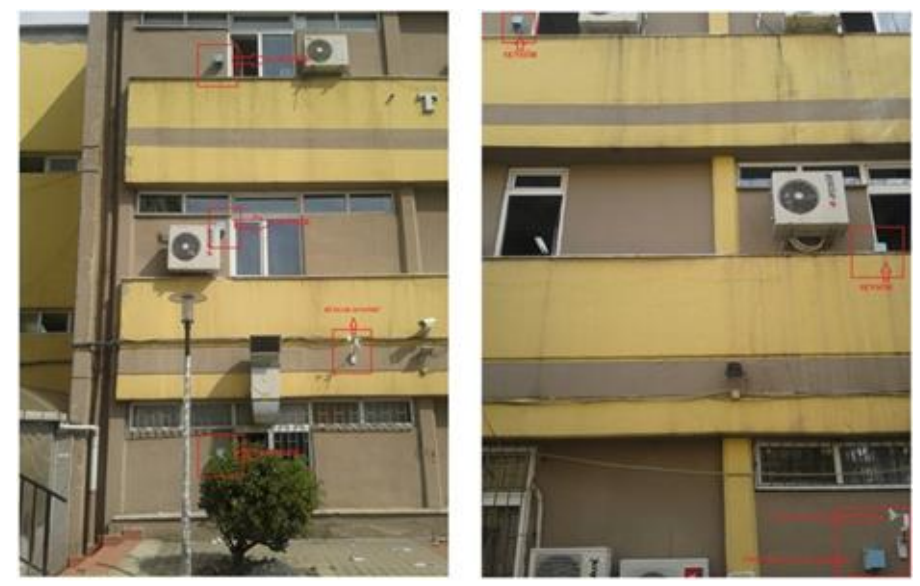

Şekil 4. T.E.F. Cepheden Görünüm

\section{Deneysel Çalışma}

Marmara Üniversitesi’nde bulunan eski tarihli inşası gerçekleşen binalardan Teknik Eğitim Fakültesi A Blok zemin kat, 1.kat güney ve kuzey cephede, iç ve dış tarafta ve yeni binalardan Mühendislik Fakültesi C Blok 3.kat kuzey ve 2. Kat güney cephede, iç ve dış tarafta higro-sensörler kullanılarak sıcaklıklar ölçülmüştür. Mühendislik Fakültesi ve Teknik Eğitim Fakültesi'nin kuzey ve güney cephelerinde yapılan dış sıcaklık ölçümleri tablolarda kanal 1, kanal 2, kanal 3 adı verilen sütunlarda gösterilirken, adı geçen laboratuarların iç sıcaklık ölçümü iç sıcaklık olarak ilk sütunda gösterilmiştir. İç sıcaklıkların alındığ1 cihazların katlarında bulunan higro-sensörlerin dış sıcaklık ölçümleri ise güney cephelerde kanal 2 kuzey cephelerde ise kanal 1 sütunlarındaki sıcaklık verileri alınarak günlük ortalama iç ve dış sıcaklık tabloları hazırlanmıştır. $\mathrm{Bu}$ ortalama değerlerin yanında sıcaklık fark değerleri de tabloda gösterilmiştir. $\mathrm{Bu}$ tablolarda yer verilen sıcaklık farkları kullanılarak çalışmaya konu olan iki binada kuzey ve güney cephelerinde bulunan mahallerin her biri için günlük 1sı kaybı hesap tabloları hazırlanmıştır. Bu çalışmada hesaplamalarda kullanılan denklemler aşağıda denklem (1-4)' de verilmiştir.

$\mathrm{Q}_{\text {top }}=\mathrm{Q}_{\mathrm{i}}+\mathrm{Q}_{\mathrm{s}}$

\section{Burada;}


$\mathrm{Q}_{\text {top }}$, Odanın toplam 1s1 kaybını

$\mathrm{Q}_{\text {i }}$, İletimsel 1s1 kaybın1

$\mathrm{Q}_{\mathrm{s}}$, Hava sızıntısı 1sı kaybını ifade etmektedir.

$\mathrm{Q}_{\mathrm{i}}=\mathrm{Q}_{\mathrm{o}}\left(1+\mathrm{Z}_{\mathrm{D}}+\mathrm{Z}_{\mathrm{H}}+\mathrm{Z}_{\mathrm{W}}\right)$

Burada;

$\mathrm{Q}_{0}$, Yapı bileşenlerinden iletim ve taşınım ile olan 1sı kayb1

$\mathrm{Z}_{\mathrm{D}}$, Birleştirilmiş artırım katsayısını

$\mathrm{Z}_{\mathrm{H}}$, Yön artırım katsayısını

$\mathrm{Z}_{\mathrm{W}}$, Yüksek kat artırım katsayısını

ifade etmektedir.

$\mathrm{Q}_{\mathrm{o}}=\sum \mathrm{KA}\left(\mathrm{T}_{\mathrm{iç}}-\mathrm{T}_{\mathrm{d}}\right)$

Burada;

$\mathrm{K}$, Yapı bileşenlerinin toplam 1sı geçiş katsayısı

A, Yapı bileşeninin alanını

$\mathrm{T}_{\mathrm{iç}}$, İç ortam sıcaklığını

$\mathrm{T}_{\mathrm{d}}$, Dış ortam sıcaklığını

ifade etmektedir.

$\mathrm{Q}_{\mathrm{s}}=\sum(\mathrm{aL}) \mathrm{RH}\left(\mathrm{T}_{\mathrm{i}}-\mathrm{T}_{\mathrm{d}}\right) \mathrm{Z}_{\mathrm{e}}$

Burada;

a, hava sızıntı katsayısını $\left(\mathrm{m}^{3} / \mathrm{mh}\right)$

L, Kapı ve pencerelerin açılan kısımlarının metre olarak çevre uzunluğunu (m)

$\mathrm{R}$, Oda durum katsayısını (birimsiz)

$\mathrm{H}$, Bina durum katsayısın $1\left(\mathrm{Wh} / \mathrm{m}^{30} \mathrm{C}\right)$

$\mathrm{T}_{\mathrm{i}}, \mathrm{T}_{\mathrm{d}}$, iç ve diş sıcaklıkları $\left({ }^{\circ} \mathrm{C}\right)$

$\mathrm{Z}_{\mathrm{e}}$, Birimsiz katsayını

ifade etmektedir. 
Şekil 5’te ölçüm yapılan laboratuarların detayı görülmektedir.

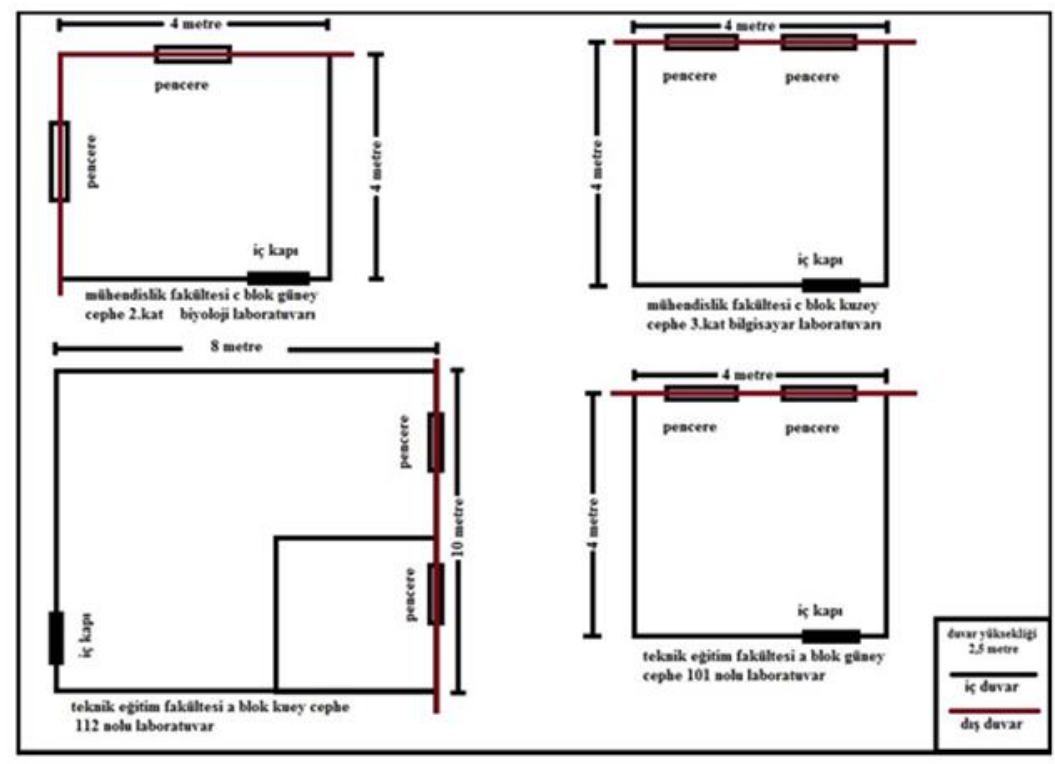

Şekil 5. Laboratuvarların Detayı

Isı kaybı hesapları yapılırken, Tablo 2'deki İstanbul iline ait kış sıcaklığı esas alınır. Bina durum katsayısı (H) ise Tablo 3'ten alınmıştır [14].

Tablo 2. Türkiye'de İl ve İlçelerin Tasarıma Esas Kış Sıcaklıkları

\begin{tabular}{|c|c|c|c|c|c|c|c|}
\hline Merkez & Sicaklık ${ }^{\circ} \mathrm{C}$ & Merkez & Sicaklık ${ }^{\circ} \mathrm{C}$ & Merkez & Sicaklık ${ }^{\circ} \mathrm{C}$ & Merkez & Sicaklık ${ }^{\circ} \mathrm{C}$ \\
\hline ISPARTA & -9 & Keșan & $-6 R$ & Milis & $0 \mathrm{R}$ & SAMSUN & $-3 R$ \\
\hline Idil & -6 & Keşap & -3 & Mucur & -12 & Sandıklı & -12 \\
\hline Ikizdere & .9 & Kibrisçık & -12 & Mudanya & $-3 \mathrm{R}$ & Sapanca & $-3 \mathrm{R}$ \\
\hline Iliç & -18 & Kinik & $-3 R$ & MUGLA & $-3 R$ & Sultanhisar & -3 \\
\hline Imranlı & -18 & Kınkhan & $0 \mathrm{R}$ & Mudurnu & -9 & Suluova & -12 \\
\hline Imroz & $-3 \mathrm{R}$ & KIRIKKALE & -12 & Muradiye & -18 & Sungurlu & -15 \\
\hline Incesu & -15 & Kurkaģaç & -3 & Muratlı & $-6 R$ & Suruç & $-6 R$ \\
\hline Inebolu & $-3 R$ & KIRȘEHIR & -12 & M. Kemalpaşa & $-6 R$ & Susurluk & -15 \\
\hline Inegol & $-9 \mathrm{R}$ & Kizilcahamam & -12 & Mut & -9 & Suşehri & -15 \\
\hline Ipsala & $-9 \mathrm{R}$ & Kiziltepe & -6 & Mutki & 15 & Surmene & -3 \\
\hline Iskenderun & +3 & Kiğ1 & -18 & MUȘ & -18 & Sutçuler & -9 \\
\hline Iskilip & -15 & Kilis & -6 & Nallihan & -12 & Şabanơzu & -15 \\
\hline Islahiye & -3 & Kiraz. & -3 & Narman & -24 & Şankaya & -21 \\
\hline Ispir & -18 & Koçarhı & $-3 \mathrm{R}$ & Nazilli & -3 & Șarkikaraağaç & -12 \\
\hline ISTANBUL & $-3 \mathrm{R}$ & KONYA & -12 & Nazimiye & -18 & Şarkoy & $-3 \mathrm{R}$ \\
\hline Ivrindi & $-3 \mathrm{R}$ & Korkuteli & -9 & NEVŞEHIR & -15 & Şarkışla & -18 \\
\hline IZMIR & 0 & Koycegiz & $-3 \mathrm{R}$ & NIGDE & $-15 \mathrm{R}$ & Șavșat & -12 \\
\hline IZMIT & $-3 \mathrm{R}$ & Koyulhisar & -12 & Niksar & -12 & Şebinkarahisar & -12 \\
\hline Iznik & $-3 \mathrm{R}$ & Kozaklı & -15 & Nizip & $-6 R$ & Șefaath & -15 \\
\hline Kadikoy & $-3 R$ & Kozan & $-3 R$ & Nusaybin & $-6 R$ & Şemdinli & -27 \\
\hline Kadinhan & -12 & Kozluk & -12 & Oguzzeli & -9 & Şereflikoçhisar & 12 \\
\hline Kağızman & -24 & Kula & -6 & Of & -3 & ȘIRNAK & -6 \\
\hline
\end{tabular}


Tablo 3. Bina Durum Katsayısı (H) $\left(\mathrm{kcal} / \mathrm{m}^{3}{ }^{\circ} \mathrm{C}\right)$

\begin{tabular}{|l|c|c|c|}
\cline { 3 - 4 } \multicolumn{2}{c|}{} & \multicolumn{2}{c|}{ Bina durumu katsayısı } \\
\hline Bölgenin durumu & Binamm durumu & Bitișik nizam & Aynk nizam \\
\hline Normal bölge & Mahfuz & 0.24 & 0.34 \\
\hline & Serbest & 0.41 & 0.58 \\
\hline & Çok serbest & 0.60 & 0.84 \\
\hline Rüzgarlı bölge & Mahfuz & 0.41 & 0.58 \\
\hline & Serbest & 0.60 & 0.84 \\
\hline & Çok serbest & 0.62 & 1.13 \\
\hline
\end{tabular}

Şekil 6'da iletim ve taşınım yoluyla ısı geçişi şematik olarak gösterilmiştir.

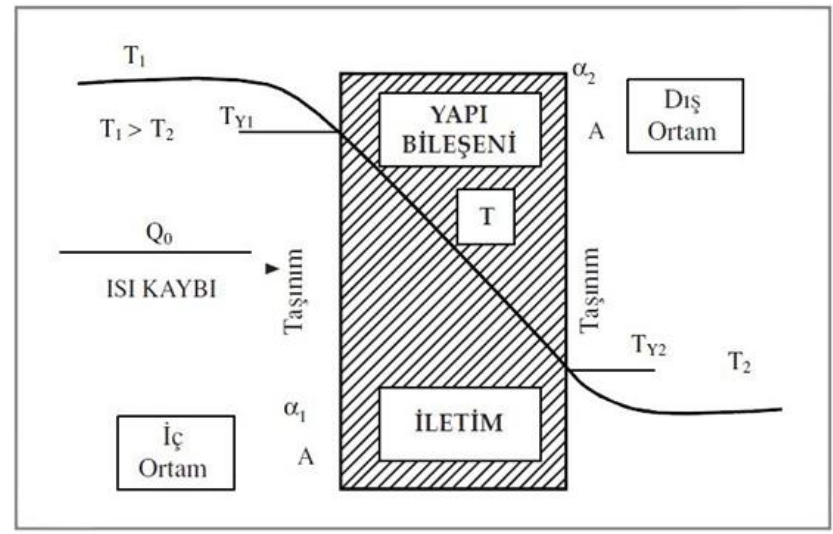

Şekil 6. İletim ve Taşınım Yoluyla Isı Geçişi

Tablo 2'den İstanbul iline ait sıcaklık -3R olup bu değere göre rüzgarlı ve binanın konumuna göre serbest ayrık nizam bina durum katsayısı $\mathrm{H}=0.84$ alınmıştır [14].

Bir yapı bileşenin toplam ısı iletim katsayının denklem 5'e göre bulunur.

$\frac{1}{\mathrm{~K}}=\frac{1}{\alpha_{\mathrm{ic}}}+\frac{\mathrm{d}_{1}}{\lambda_{1}}+\frac{\mathrm{d}_{2}}{\lambda_{2}}+\cdots \frac{\mathrm{d}_{\mathrm{n}}}{\lambda_{\mathrm{n}}}+\frac{1}{\alpha_{\mathrm{d} \}}$

Burada,

K, Yapı bileşeninin toplam 1sı iletim katsayısını,

$\lambda$, Yap1 elemanlarının 1s1 iletim katsayılarını,

$\alpha$, İç ve dış taraftaki ısı taşınım katsayılarını,

d : Yapı elemanlarının kalınlıklarını,

ifade etmektedir.

Şekil 7'de yalıtımsız ve yalıtımlı duvar örnkleri görülmektedir. 


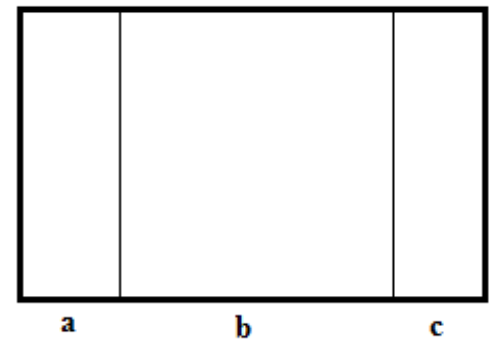

a) Yalıtımsız Dıș Duvar

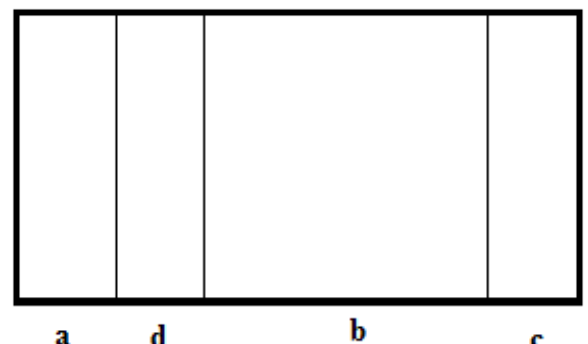

a. Diș siva: $2 \mathrm{~cm}, \mathrm{k}=0.75 \mathrm{kcal} / \mathrm{mh}^{\circ} \mathrm{C}$ b. Delikli tuğla: $29 \mathrm{~cm}, \mathrm{k}=0.40 \mathrm{kcal} / \mathrm{mh}^{\circ} \mathrm{C}$ c. İc sıva: $2 \mathrm{~cm}, \mathrm{k}=0.65 \mathrm{kcal} / \mathrm{mh}^{\circ} \mathrm{C}$

d. Rende talași: $2 \mathrm{~cm}, \mathrm{k}=0.13 \mathrm{kcal} / \mathrm{mh}^{\circ} \mathrm{C}$

Şekil 7.a'da görülen yalıtımsız duvar için ısı geçirme katsayısı;

$\frac{1}{\mathrm{~K}}=\frac{1}{7}+\frac{0.02}{0.65}+\frac{0.29}{0.4}+\frac{0.02}{0.75}+\frac{1}{20} \rightarrow K=1.025 \mathrm{kcal} / \mathrm{m}^{2} \mathrm{~h}^{\circ} \mathrm{C}$

Şekil 7.b'de görülen yalıtımlı duvar için 1sı geçirme katsayısı;

$\frac{1}{\mathrm{~K}}=\frac{1}{7}+\frac{0.02}{0.65}+\frac{0.29}{0.4}+\frac{0.02}{0.13}+\frac{0.02}{0.75}+\frac{1}{20} \rightarrow K=0.886 \mathrm{kcal} / \mathrm{m}^{2} \mathrm{~h}^{\mathrm{o}} \mathrm{C}$

Şekil 8'de yalıtımsız ve yalıtımlı tavan-döşeme örnekleri görülmektedir.

\begin{tabular}{|c|}
\hline $\mathbf{a}$ \\
\hline $\mathbf{b}$ \\
\hline $\mathbf{c}$ \\
\hline $\mathrm{d}$ \\
\hline
\end{tabular}

a. Ahșap parke: $1 \mathrm{~cm}, \mathrm{k}=0.13 \mathrm{kcal} / \mathrm{mh}^{\circ} \mathrm{C}$

b. Harç: $2 \mathrm{~cm}, \mathrm{k}=1.2 \mathrm{kcal} / \mathrm{mh}^{\circ} \mathrm{C}$

c. Betonarme betonu: $10 \mathrm{~cm}, \mathrm{k}=1.8 \mathrm{kcal} / \mathrm{mh}^{\circ} \mathrm{C}$ d. Siva: $2 \mathrm{~cm}, \mathrm{k}=0.65 \mathrm{kcal} / \mathrm{mh}^{\circ} \mathrm{C}$

e. Rende talașı levha: $13 \mathrm{~cm}, \mathrm{k}=0.08 \mathrm{kcal} / \mathrm{mh}^{\circ} \mathrm{C}$

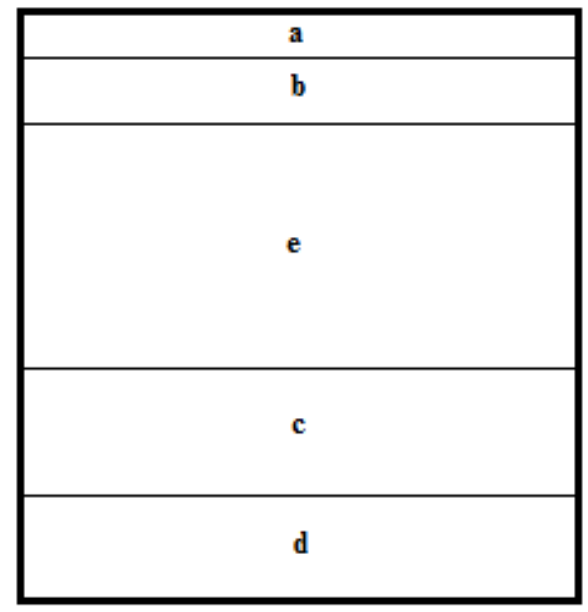

a) Yalıtımsız tavan döşeme

b) Yalıtımlı tavan döşeme

Şekil 8. Döşeme Örnekleri

Şekil 8.a'da gözüken yalıtımlı tavan için 1sı iletim katsayısı;

$\frac{1}{\mathrm{~K}}=\frac{1}{7}+\frac{0.02}{0.65}+\frac{0.10}{1.8}+\frac{0.13}{0.08}+\frac{0.02}{1.2}+\frac{0.01}{0.13}+\frac{1}{7} \rightarrow K=0.478 \mathrm{kcal} / \mathrm{m}^{2} \mathrm{~h}^{\circ} \mathrm{C}$

Şekil 8.b'de gözüken yalıtımsız tavan için 1sı iletim katsayısı; 
$\frac{1}{\mathrm{~K}}=\frac{1}{7}+\frac{0.02}{0.65}+\frac{0.10}{1.8}+\frac{0.02}{1.2}+\frac{0.01}{0.13}+\frac{1}{7} \rightarrow K=2.148 \mathrm{kcal} / \mathrm{m}^{2} \mathrm{~h}^{\mathrm{O}} \mathrm{C}$

Şekil 8.a'da gözüken yalıtımsız döşeme için ısı iletim katsayısı;

$\frac{1}{\mathrm{~K}}=\frac{1}{5}+\frac{0.02}{0.65}+\frac{0.10}{1.8}+\frac{0.02}{1.2}+\frac{0.01}{0.13}+\frac{1}{5} \rightarrow K=1.724 \mathrm{kcal} / \mathrm{m}^{2} \mathrm{~h}^{\circ} \mathrm{C}$

Şekil 8.b'de gözüken yalıtımlı döşeme için 1sı iletim katsayısı;

$\frac{1}{\mathrm{~K}}=\frac{1}{5}+\frac{0.02}{0.65}+\frac{0.10}{1.8}+\frac{0.13}{0.08}+\frac{0,02}{1.2}+\frac{0,01}{0.13}+\frac{1}{5} \rightarrow K=0.454 \mathrm{kcal} / \mathrm{m}^{2} \mathrm{~h}^{\mathrm{o}} \mathrm{C}$

Yüzey 1sı taşınım katsayıları $(\alpha)$ ve pencere ve kapılar için toplam ısı geçiş katsayıları Tablo 4 ve 5'ten alınmıştır. Ayrıca 1sı kaybı hesabında yapı bileşenleri için kullanılan semboller Tablo 6'da gösterilmiştir.

Tablo 4. DIN 4701'e göre Yüzey Isı Taşınım Katsayıları $\left(\alpha, \mathrm{kcal} / \mathrm{m}^{2} \mathrm{~h}^{\circ} \mathrm{C}\right)$

\begin{tabular}{|c|c|c|c|}
\hline \multicolumn{2}{|l|}{ Durum } & $\begin{array}{c}\text { Film } \\
\text { Katsayis1 } \\
\mathrm{kcal} / \mathrm{m}^{2} \mathrm{~h}{ }^{\circ} \mathrm{C}\end{array}$ & $\begin{array}{c}\text { Isıl } \\
\text { Direnç } \\
\mathrm{m}^{2} \mathrm{~h}^{\circ} \mathrm{C} / \mathrm{kcal}\end{array}$ \\
\hline $\begin{array}{c}\text { iç } \\
\text { ortam }\end{array}$ soguk & $\begin{array}{l}\text { İ̧̧ yüzeyler } \\
\text { Isı geçişi yatay } \\
\text { veya yukarı }\end{array}$ & 7 & 0.14 \\
\hline $\begin{array}{c}\text { iç } \\
\text { ortam } \\
\text { sicak } \\
\text { soğuk }\end{array}$ & $\begin{array}{l}\text { İç yüzeyler } \\
\text { Isı geçişi aşağı }\end{array}$ & 5 & 0.20 \\
\hline soğuk & $\begin{array}{l}\text { Bütün dış } \\
\text { yüzeyler }\end{array}$ & 20 & 0.05 \\
\hline
\end{tabular}

Tablo 5. Pencere ve Kapılar için Toplam Isı Geçiş Katsayıları 


\begin{tabular}{|c|c|}
\hline PENCERE Ve KAPILAR & $\begin{array}{l}\text { ISI GEÇIRME KATSAYISI } \\
\text { (U) } \mathrm{kcal} / \mathrm{m}^{2} \mathbf{h}^{\circ} \mathrm{C}\end{array}$ \\
\hline \multicolumn{2}{|l|}{ AHSSAP PENCERE ve KAPILAR } \\
\hline Basit tek camlı pencere (TP) ve dış kapı (DK) & 4.5 \\
\hline Ozel birleștirilmiş çift camlı pencere (ÇCP) ve dış kapı (DK) (iki cam arası 6 mm) & 2.8 \\
\hline Ozel birleștirilmiş çift camlı pencere (ÇCP) ve dış kapı (DK) (iki cam arası $12 \mathrm{~mm}$ ) & 2.5 \\
\hline Camsı dış kapı (DK) & 3.0 \\
\hline Bitişik (muntabık) çift kanatlı pencere (ÇP) ve dış kapı (DK) & 2.2 \\
\hline Kasalı çift kanatlı pencere (ÇP) ve dış kapı (DK) & 2.2 \\
\hline \multicolumn{2}{|l|}{ METAL PENCERE Ve KAPILAR } \\
\hline \multicolumn{2}{|l|}{ (Hazır profillerinden en az iki binili) } \\
\hline Basit tek camlı pencere (TP) ve dış kapı (DK) & 5.0 \\
\hline Ozel birleștirilmiş çift camlı pencere (ÇCP) ve dış kapı (DK) (iki cam arası 6 mm) & 3.4 \\
\hline Ozel birleștirilmiş çift camlı pencere (ÇCP) ve dış kapı (DK) (iki cam arası $12 \mathrm{~mm}$ ) & 3.1 \\
\hline Bitişik (muntabık) çift kanatlı pencere (ÇP) ve dış kapı (DK) & 3.0 \\
\hline Kasalı çift kanatı pencere (ÇP) ve dıș kapı (DK) & 2.8 \\
\hline Tepe penceresi (basit) (TP) & 5.0 \\
\hline Tepe penceresi (çift) (TP) & 3.0 \\
\hline \multicolumn{2}{|l|}{ PLASTIK (PVC) PENCERELER } \\
\hline Basit tek camlı pencere (TP) ve dış kapı (DK) & 4.3 \\
\hline Ozel birlesțirilmiş çift camlı pencere (ÇCP) & 2.2 \\
\hline
\end{tabular}

Tablo 6. Isı Kaybı Hesabında Yapı Bileşenleri İçin Kullanılan Semboller

\begin{tabular}{|l|l|}
\hline Sembol & Anlam \\
\hline TP & Tek Pencere \\
\hline ÇP & Çift Pencere \\
\hline ÇCP & Çift Camlı Pencere \\
\hline DK & Dış Kapı \\
\hline IK & İç Kapı \\
\hline BK & Balkon Kapısı \\
\hline BDD & Bitişik Dış Duvar \\
\hline KD & Komşu Duvar \\
\hline DD & Dış Duvar \\
\hline ID & İç Duvar \\
\hline Ta & Tavan \\
\hline Dö & Döşeme \\
\hline
\end{tabular}

Dışarıya açılan pencerelerin alanlarının iç kapı alanına oranı hesaplanırsa; $\mathrm{Ap} / \mathrm{Ak}=2 \mathrm{x}(1.4 \mathrm{x} 1.3) /(12.2)=1.654$ aralıklı tahta veya pvc iç kapı için Tablo 7'den oda durum katsayı1 $\mathrm{R}=0.9$ olarak bulunur.

Kapı ve pencerelerin sızdırmazlık katsayısı, birleştirilmiş artırım katsayısı $\left(Z_{D}\right)$, kat yükseklik artırım değeri ve yön artırım tablosu $\left(Z_{H}\right)$ sırasıyla Tablo 8, Tablo 9, Tablo10 ve Tablo 11'den alınmıştır [14].

Tablo 7. Oda Durum Katsayısı (R) 


\begin{tabular}{|c|c|c|c|}
\hline & \multirow{2}{*}{ İç kapı } & $A_{D P}(D ı s ̧$ Pencere Alanı) & \multirow{2}{*}{$\mathbf{R}$} \\
\hline & & AIK (Iç kapı alanı) & \\
\hline \multirow{2}{*}{$\begin{array}{c}\text { Tahta veya plastik } \\
\text { çerçeve }\end{array}$} & Aralıklı & $\mathrm{A}_{\mathrm{DP}} / \mathrm{A}_{\mathrm{IK}}<3$ & 0.9 \\
\hline & Aralıksız & $\mathrm{A}_{\mathrm{DN}} / \mathrm{A}_{I \mathrm{~K}}<1.5$ & 0.9 \\
\hline \multirow{2}{*}{$\begin{array}{c}\text { Çelik veya metal } \\
\text { çerçeve }\end{array}$} & Aralıklı & $\mathrm{A}_{\mathrm{DP}} / \mathrm{A}_{\mathrm{IK}}<6$ & 0.9 \\
\hline & Aralıksız & $\mathrm{A}_{\mathrm{DP}} / \mathrm{A}_{\mathrm{IK}}<2.5$ & 0.9 \\
\hline \multirow{2}{*}{$\begin{array}{c}\text { Tahta veya plastik } \\
\text { çerçeve }\end{array}$} & Aralıklı & $3<A_{D N} / A_{I K}<9$ & 0.7 \\
\hline & Aralıksız & $1.5<\mathrm{A}_{\mathrm{DP}} / \mathrm{A}_{1 K}<3$ & 0.7 \\
\hline \multirow{2}{*}{$\begin{array}{c}\text { Çelik veya metal } \\
\text { çerçeve }\end{array}$} & Aralıklı & $6<\mathrm{A}_{\mathrm{DP}} / \mathrm{A}_{I \mathrm{~K}}<20$ & 0.7 \\
\hline & Aralıksız & $2.5<\mathrm{A}_{\mathrm{DN}} / \mathrm{A}_{I \mathrm{~K}}<6$ & 0.7 \\
\hline
\end{tabular}

Tablo 8. Kap1 ve Pencerelerin Sizdrmazlık Katsayıları

\begin{tabular}{|l|l|l|}
\hline Malzeme & Pencere veya kapı șekli & $\mathbf{a}\left(\mathbf{m}^{3} / \mathbf{m h}\right)$ \\
\hline \multirow{3}{*}{ Ahşap çerçeve } & Tek pencere & 3.0 \\
\cline { 2 - 3 } & Çift camlı pencere & 2.5 \\
\cline { 2 - 3 } & Çift pencere & 2.0 \\
\hline \multirow{2}{*}{ Plastik çerçeve } & Tek veya çift camlı pencere & 2.0 \\
\cline { 2 - 3 } & Tek pencere & 1.5 \\
\hline \multirow{2}{*}{ Çelik veya metal çerçeve } & Çift camlı pencere & 1.2 \\
\cline { 2 - 3 } & Cift pencere & 1.2 \\
\hline \multirow{2}{*}{ Iç kapılar } & Eşiksiz kapılar & 40.0 \\
\cline { 2 - 3 } & Eşikli kapılar & 15.0 \\
\hline
\end{tabular}

$$
D=\frac{\mathrm{Q}_{0}}{\mathrm{~A}_{\mathrm{top}}\left(T_{i c ̧}-T_{d \iota \varsigma}\right)}
$$

Bu denklemde;

Q $\quad$ : Artırımsı1 1s1 kayb1 (kcal/h)

$\mathrm{A}_{\text {top }} \quad$ : Isı kaybı hesaplanan hacmi çevreleyen tüm yüzeylerin alanları

$\mathrm{T}_{\mathrm{iç}}-\mathrm{T}_{\mathrm{d} ı ̧}:$ İç ve dış sıcaklık arasındaki fark $\left({ }^{\circ} \mathrm{C}\right)$

$\mathrm{D}: \mathrm{Z}_{\mathrm{D}} \quad$ : Artırımında kullanılan katsayı $\left(\mathrm{kcal} / \mathrm{m}^{2} \mathrm{~h}^{\circ} \mathrm{C}\right)$ 
Tablo 9. Birleştirilmiş Artırım Katsayısı $\left(Z_{D}\right)$

\begin{tabular}{|l|l|l|l|l|}
\hline \multirow{2}{*}{ Işletme Durumu } & \multicolumn{5}{|c|}{$\mathrm{D}\left(\mathrm{kcal} / \mathrm{m}^{2} \mathrm{~h}^{\circ} \mathrm{C}\right)$} \\
\cline { 2 - 5 } & $0.12-0.34$ & $0.35-0.80$ & $0.81-1.73$ & 1.74 \\
\hline \multicolumn{5}{|c|}{$\% \mathrm{Z}_{\mathrm{D}}$} \\
\hline 1. Işletme & 7 & 7 & 7 & 7 \\
\hline 2. Işletme & 20 & 15 & 15 & 15 \\
\hline 3. Işletme & 30 & 25 & 20 & 15 \\
\hline
\end{tabular}

$\mathrm{Z}_{\mathrm{E}}$, her iki duvarında pencere olan odalar için 1.2 diğer odalar için 1 katsayısı kullanılmaktadır.

Tablo 10. Kat Yükseklik Artırım Tablosu

\begin{tabular}{|c|c|c|c|c|c|c|c|c|c|c|c|c|}
\hline$\frac{\text { Kat }}{\text { Arturm }}$ & 4 & 5 & 6 & 7 & 8 & 9 & 10 & 11 & 12 & 13 & 14 & 15 \\
\hline $0 \%$ & 3.2 .1 & 3.2 .1 & 3.2 .1 & 3.2 .1 & 3.2 .1 & 3.2 .1 & 3.2 .1 & 3.2 .1 & 3.2 .1 & 3.2 .1 & 4.3.2.1 & 5.4 .3 .2 .1 \\
\hline $5 \%$ & 4. & 4. & 5.4 . & 5.4 . & 5.4 . & 6.5 .4 & 6.5 .4 & 6.5 .4 & 6.5 .4 & 6.5 .4 & 7.6 .5 & 8.7 .6 \\
\hline $10 \%$ & & 5. & 6. & 6. & 7.6. & 8.7. & 9.8 .7 & 9.8 .7 & 9.8 .7 & 9.8 .7 & 10.9 .8 & 11.10 .9 \\
\hline $15 \%$ & & & & 7. & 8. & 9. & 10. & 10. & 11.10 & 12.11 .10 & 13.12 .11 & 14.13 .12 \\
\hline $20 \%$ & & & & & & & & 11. & 12. & 13. & 14. & 15. \\
\hline
\end{tabular}

Tablo 11. Yön Artırım Tablosu $\left(\mathrm{Z}_{\mathrm{H}}\right)$

\begin{tabular}{|l|c|c|c|c|c|c|c|c|}
\hline YON & $\mathrm{G}$ & $\mathrm{GB}$ & $\mathrm{B}$ & $\mathrm{KB}$ & $\mathrm{K}$ & $\mathrm{KD}$ & $\mathrm{D}$ & $\mathrm{GD}$ \\
\hline $\mathrm{CZ}_{\mathrm{H}}$ & -5 & -5 & 0 & 5 & 5 & 5 & 0 & -5 \\
\hline
\end{tabular}

Şekil 9' da kapı ve pencere detayları gösterilmiştir.

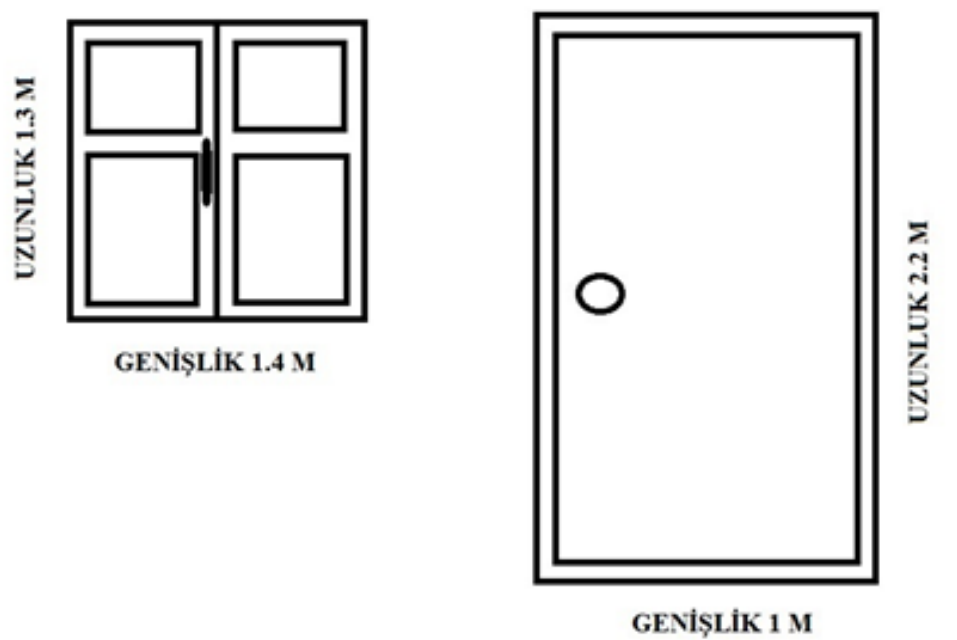

Şekil 9. Kapı ve Pencere Detayı 
Tablo 12-15'te belli tarihlerdeki M.Ü. Teknik Eğitim Fakültesi ve Mühendislik Fakültesinin farklı katlardaki mahalleri için oluşturulan sonuçlar sunulmuş olup, Teknik Eğitim Fakültesi A Blok 112 ve 101 nolu laboratuvarları Mühendislik Fakültesi C Blok 2.kat Biyoloji Laboratuvarı ve 3. kat Bilgisayar Laboratuvarlarının günlük olarak iç ve dış sıcaklıkları ile 1sı kaybı hesap tablolarından mahallerin mertebeleri gösterilmiştir.

Tablo 12. İki Binanın Güney Cephelerinin Isı Kaybı Miktarları

\begin{tabular}{|c|c|c|c|c|}
\hline Tarih & $\mathbf{0 3 . 0 3 . 2 0 1 4}$ & $\mathbf{0 4 . 0 3 . 2 0 1 4}$ & $\mathbf{0 5 . 0 3 . 2 0 1 4}$ & $\mathbf{0 6 . 0 3 . 2 0 1 4}$ \\
\hline Biyoloji Lab. (2.Kat) & $574.4 \mathrm{~W}$ & $846.4 \mathrm{~W}$ & $726.9 \mathrm{~W}$ & $725.8 \mathrm{~W}$ \\
\hline $\begin{array}{c}\text { A-101 No'lu Sinıf } \\
\text { (Zemin Kat) }\end{array}$ & $663.8 \mathrm{~W}$ & $1094.5 \mathrm{~W}$ & $880.2 \mathrm{~W}$ & $934.0 \mathrm{~W}$ \\
\hline
\end{tabular}

Tablo 13. İki Binanın Güney Cephelerinin Günlük Ortalama İç ve Dış Sıcaklık Farkı Miktarları

\begin{tabular}{|c|c|c|c|c|}
\hline Tarih & $\mathbf{0 3 . 0 3 . 2 0 1 4}$ & $\mathbf{0 4 . 0 3 . 2 0 1 4}$ & $\mathbf{0 5 . 0 3 . 2 0 1 4}$ & $\mathbf{0 6 . 0 3 . 2 0 1 4}$ \\
\hline Biyoloji Lab. (2.Kat) & $23.2-16.75$ & $23.17-13.67$ & $23.23-15.07$ & $23.85-15.70$ \\
\hline $\begin{array}{c}\text { A-101 No'lu Sinif } \\
\text { (Zemin Kat) }\end{array}$ & $22.63-16.23$ & $22.23-16.21$ & $22.00-14.50$ & $22.63-16.23$ \\
\hline
\end{tabular}

Tablo 14. İki Binanın Kuzey Cephelerinin Isı Kaybı Miktarları

\begin{tabular}{|c|c|c|c|c|}
\hline Tarih & $\mathbf{0 3 . 0 3 . 2 0 1 4}$ & $\mathbf{0 4 . 0 3 . 2 0 1 4}$ & $\mathbf{0 5 . 0 3 . 2 0 1 4}$ & $\mathbf{0 6 . 0 3 . 2 0 1 4}$ \\
\hline Bilgisayar Lab. (3.Kat) & $813.5 \mathrm{~W}$ & $1047.0 \mathrm{~W}$ & $911.6 \mathrm{~W}$ & $957.2 \mathrm{~W}$ \\
\hline $\begin{array}{c}\text { A-112 No'lu } \\
\text { Ak1ş. Mek. Lab. } \\
\text { (Zemin Kat) }\end{array}$ & 1102.3 & 1157.3 & 1044.5 & 1169.5 \\
\hline
\end{tabular}

Tablo 15. İki Binanın Kuzey Cephelerinin Günlük Ortalama İç ve Dış Sıcaklık Farkı Miktarları

\begin{tabular}{|c|c|c|c|c|}
\hline Tarih & $\mathbf{0 3 . 0 3 . 2 0 1 4}$ & $\mathbf{0 4 . 0 3 . 2 0 1 4}$ & $\mathbf{0 5 . 0 3 . 2 0 1 4}$ & $\mathbf{0 6 . 0 3 . 2 0 1 4}$ \\
\hline Bilgisayar Lab. (3.Kat) & $23.12-14.66$ & $23.5-12.60$ & $23.48-14.00$ & $23.16-13.20$ \\
\hline $\begin{array}{c}\text { A-112 No'lu } \\
\text { Ak1ş. Mek. Lab. } \\
\text { (Zemin Kat) }\end{array}$ & $21.83-15.25$ & $22.34-13.53$ & $22.5-14.68$ & $21.48-13.42$ \\
\hline
\end{tabular}

Kuzey cephede farklı tarihlerde ölçülen dış sıcaklığın güney cepheye göre daha düşük olduğu tablolardan net bir şekilde görülmektedir. Bu durum Tablo 12 ve Tablo 14'te görüldügüü üzere kuzey cephede oluşan 1sı kaybınının daha yüksek olduğu anlamına gelmektedir.

\section{Sonuçlar}

Çalışmada ülkemiz adına çok fazla öneme sahip olan enerji konusuyla ilgili olarak; enerji tüketiminde önemli bir yer tutan binaların, söz konusu bina yalıtımının sebep olduğu enerji tasarrufu ortaya konulmuş olup binalarda 1sı yalıtımının zaruri bir uygulama olduğu gösterilmiştir. Farklı iki kamu binasında yapılan ölçümler ile olası bina yalıtımının bina iç ortamına etkisi anlatılmıştır. Böylece bina yalıtımının önemli bir şekilde enerji tasarrufu sağladığını gözler önüne serilmiştir. 
$\mathrm{Bu}$ çalışmada, mahallerin iç sıcaklık ölçümleri meteoroloji sette bulunan ana konsol tarafindan, diş tarafindaki sıcaklık ölçümleri ise termo-higro sensörler ile yapılmıştır. Elde edilen sıcaklık ölçümleri ile günlük ortalama sıcaklık tabloları hazırlanarak farklı cephelerdeki sıcaklık farkları gösterilmiştir. Böylelikle yetersiz cam kullanımından, kötü ve kalitesiz malzemeyle yapılmış pencerelerden kaynaklanan binalarda büyük öneme sahip havalandırma kaybının yanı sıra cephenin enerji etkinliğine de özel bir dikkat çekilmiştir. Çalı̧̧mada, elde edilen ölçümlerle enerji kayıplarının; havalandırma kayıpları, cam ve pencerelerin kalitesi, binada kullanılan malzemelerin kalitesi arasındaki ilişkiler incelenmiştir. Isınma için enerji tüketimi ölçümleri ile hesaplanan değerler karşılaştırılmıştır. Buna göre farklı tarihlerde ve farklı malzeme yapısının enerji verimliliği açısından incelenmesi sağlanmıştır. Sicaklık fark tablolarında dört günlük ortalama değerleri topladığımız zaman kuzey cephede $31.28{ }^{\circ} \mathrm{C}$ bir veri elde edilirken güney cephede $24.47{ }^{\circ} \mathrm{C}$ lik bir veri elde edildi. Bu veride gayet açık bir şekilde farklı cephelerde meydana gelen sıcaklık farklılıklarını görülmüştür. Elde edilen veriler dört günün her saatinde alınan verilerdir. Dolayısıyla gece ve gündüz ortalama sıcaklık fark verileridir. Mevsime havanın kapalı veya açık olmasına göre meydana gelen sıcaklık farklılıkları çok daha fazla olacaktır. Tablo 3.31'deki Toplam 1sı kayıp tablosuda buna paralel veriler vermektedir. Aynı binaya T.E.F'e ait kuzey ve güney cephelede bulunan laboratuvarlardaki 1sı kayıpları da farklı cephelerdeki ısı kayıplarının ne denli gerçekleştiğini ortaya açıkça koymaktadır. Ayrıca Tablo 12-15'te yeni kamu binası olarak incelediğimiz Mühendislik Fakültesi C Blok ve yapımı çok daha eski olan Teknik Eğitim Fakültesi (TEF) A blokta 1sı taşınım ile meydana gelen kayıplar ortaya konulmuştur. Bu tablolar arasındaki fark bize mantolama yapılarak 1sı kayıplarının ne denli önlenebileceği konusunda fikir vermektedir.

Çalışma kapsamında yapılan ölçümler sonucunda, iki binada oluşan 1sı kayıplarında kayda değer farklıların ortaya çıktığı görülmüştür. Bu farklılıkların sebebinde aşağıda sıralanan birkaç husus ön plana çıkmaktadır:

- Binaların yalıtımlı ve yalıtımsız olması durumu 1s1 kayıplarında farklılıklar oluşturmaktadır. Hesaplamalarda yalıtımlı duvar ile yalıtımsız duvar arasında yaklaşık olarak \%20 oranında fark bulunduğu tespit edilmiştir. Bu durumun yeni kamu binasında eski kamu binasına göre daha az 1sı kayb1 olmas1 anlamina gelmektedir.

- $\quad$ Kat yüksekliği arttıkça dış sıcaklık değeri hissedilir derecede düştüğü tespit edilmiştir.

- $\quad$ Farklı cephelerde değişik sıcaklık farklılıklarının olduğu görülmüştür.

- $\quad$ Bina konumunun önemli bir fark oluşturmadığg tespit edilmiştir.

- $\quad$ Bazı mahallerde iç sıcaklıklarının yüksek çıkması o mahallerin kullanım şekline bağlı olarak kalabalık sınıf veya proses deneylerinin yapılmasından kaynaklandığı sonucuna varılmıştır.

Eski binanın yalıtımsız ve eski tip olmasından kaynaklı olarak; sonuçta, iç mahallerin ısıl konfor gereği yeni tipteki kamu binası ile aynı çeşit mahallerde benzer sıcaklık değerlerinin yakalanabilmesi için daha fazla enerji tüketimi gerekecektir.

Elde edilen veriler gösteriyor ki; günümüzün en önemli olgusu haline gelen enerji kaynaklarının maksimum verimlilikle kullanımı, enerji tüketiminde uygulanacak politikalarla gelecekte hali hazır enerji kaynakları kadar ülke ekonomisine etki edeceği aşikârdır.

Teşekkür: $\mathrm{Bu}$ çalışma Marmara Üniversitesi, Bilimsel Araştırma Projeleri Koordinasyon Biriminin (BAPKO) FEN-C-YLP 100413-0129 (Proje Ad1: TÜRKIYYE'DE ESKİ VE YENİ KAMU BINALARINDA ENERJI VERIMLİLIĞİ) numaralı projesi ile desteklenmiştir. 


\section{Kaynaklar}

[1] 2005-2006 Türkiye Enerji Raporu. (2006). Dünya Enerji Konseyi Türk Milli Komitesi, ISSN 1301-6318.

[2] http://www.iea.org/textbase/nppdf/free/2008/key_stats_2008.pdf>, Ocak 2009

[3] http://www.mmo.org.tr/resimler/dosya_ekler/a9393ba5ea45a12_ek.pdf

[4] Perez-Lombard, L., Ortiz, J., Pout, C. (2008). A Review on Buildings Energy Consumption Information, Energy and Buildings, 40, 394-398.

[5] Šumarac, D. (2009). Energy Efficiency of Buildings in Serbia (invited lecture), Proceedings, Conference Construction and Sustainable Development (Eds. S. Marinković, V. Radonjanin), DIMK, Faculty of Civil Engineering, Belgrade, 3-16.

[6] Kneifel, J. (2010). Life-Cycle Carbon and Cost Analysis of Energy Efficiency Measures in New Commercial Buildings, Energy and Buildings, 42, 333-340.

[7] Vučićević, B. (2009). Experimental and Numerical Modeling of Thermal Performance of a Residential Buildings in Belgrade, Thermal Science, 13, 245-252.

[8] http://www.eie.gov.tr/

[9] Aytaç, A. ve Aksoy U.T. (2006). Enerji Tasarrufu İçin Dış Duvarlarda Optimum Yalıtım Kalınlığı ve Isıtma Maliyet İlişkisi, Gazi Üniversitesi Mühendislik Mimarlık Fakültesi Dergisi, 21, 753-758. (13)

[10] Short T.D., Burton J.D. (2003). The Benefits of Induced Flow Solar Powered Water Pumps, Solar Energy 74, 77-84. (14)

[11] Bayraktar, M. ve Yılmaz, Z. (2008). Bina Enerji Tasarrufunda Pasif Akıllılı̆̆ın Önemi, Tesisat Mühendisligi Dergisi, 103, 5-15.

[12] Değirmenci, A.İ. (2010). Bina Yalıtım Tekniğinde Termal Kameranın Etkin Kullanımı, Yüksek Lisans Tezi, Sakarya Üniversitesi Fen Bilimleri Enstitüsü, Sakarya, Türkiye.

[13] Nexus hava istasonu işletme talimatı:

http://www.pentaotomasyon.com.tr/sayfalar.asp?LanguageID=1\&cid=3\&id=1125\&b= detay

[14] http://www.ttmd.org.tr/userfiles/dergi/ek42.pdf 